\title{
Diversity As I Say, Not As I Do: Organizational Authenticity and Diversity
}

\section{Management Effectiveness}

\author{
Andrew J. Marcinko \\ University of Durham \\ Richard J. Crisp \\ University of Durham \\ Yves Guillaume \\ Liverpool University
}

\begin{abstract}
This research examined how a misalignment between an organization's espoused values and its realized practices regarding diversity affected employees' affective commitment, organizational identification, and turnover intentions. Further, it investigated whether these relationships were mediated by perceived organizational authenticity. Using an experimental methodology, Study 1 tested the effects of both an organization's diversity management approach (espoused values) and its demographic representativeness (realized practices) on employee attitudes. The results supported a moderated mediation model such that when an organization was less demographically diverse, participants reported lower identification and commitment when the organization also expressed instrumental diversity management approach values (i.e., diversity was instrumental to the organization's primary business objectives). Further, these relationships were fully explained by the extent to which participants perceived the organization as (in)authentic. In Studies 2 and 3, an intervention was developed based on previous research involving hypocrisy and two-sided messaging. When either a university (Study 2) or a company (Study 3) included an "honest hypocrite" message acknowledging that they were not yet as diverse as they would like, it negated the negative effects of an espoused values / realized practice mismatch. Finally, Study 4 surveyed working professionals and found support for a serial mediation where the positive relationship between an organization's espoused - practiced discrepancy and employee turnover intentions was explained by perceived organizational authenticity and affective commitment / organizational identification in parallel. These findings' contribution to our understanding of diversity management effectiveness is discussed.
\end{abstract}

Keywords: Diversity, Organizational Authenticity, Inclusion, Diversity Management, Diversity Climate 


\section{INTRODUCTION}

Though diversity management (DM) — defined as the implementation of practices and policies by which an organization attempts to facilitate the positive effects and inhibit the negative effects of diversity on both performance and employee well-being — remains a prominent focus in both research and practice, it is now a stretch to describe it as an emerging area (Leslie, 2019; Olsen \& Martins, 2012). While specific figures are scarce, various reports have information-technology giant Google spending in excess of $\$ 100$ million per year on diversity and inclusion initiatives ${ }^{1}$ and estimates put the total figure spent by US companies solely on diversity training at approximately $\$ 8$ billion (Kirkland \& Bohnet, 2017). Perhaps predictably, organizations make little effort to hide these exertions; there is evidence to support the notion that firms who communicate their diversity management efforts are perceived more favorably by potential recruits (Avery, McKay, \& Volpone, 2012) and consumers (Cox \& Blake, 1991). There is also an increasing body of evidence which suggests that organizational efforts to convey diversity and inclusion practices can affect the interpersonal behaviors and attitudes of current employees (Smith, Morgan, King, Hebl, \& Peddie, 2012; Windscheid, Bowes-Sperry, Kidder, Cheung, Morner, \& Lievens, 2016), and it is well-established that diversity itself can be positively related to performance in some contexts (Guillaume, Dawson, Otaye-Ebede, Woods, \& West, 2017).

Even given the continued growth of diversity management as a focus of research and practical innovation, there remains relatively little clear guidance for organizations aiming to maximize the benefits and mitigate potential drawbacks of their increasingly diverse workforces (Guillaume et al., 2017; Leslie, 2019). Many of the world's largest and most prominent organizations openly struggle to retain and recruit diverse talent, and several have

\footnotetext{
${ }^{1}$ https://eu.usatoday.com/story/tech/2015/05/05/google-raises-stakes-diversity-spending/26868359/
} 
experienced well-publicized ${ }^{2}$, reputation-damaging ${ }^{3}$ instances $^{4}$ where their organizational climates and/or cultures were criticized for their lack of inclusivity. Many, if not most, large organizations engage in a number of similar DM practices including diversity training, mentorship programs, targeted recruitment, and others. However, research has demonstrated their effects to be mixed at best (Bezrukova et al., 2016; Kalev, Dobbin, \& Kelly, 2006).

This inconsistent efficacy is perplexing given the broad uniformity of the extensive diversity management efforts undertaken by large organizations (Kalev et al., 2006). Thus, as it has proven difficult to consistently predict the effects of individual differences or the efficacy of specific DM practices, there is value in exploring the existing literature relating to organizational-level variables impacting DM efficacy. Nearly three decades ago in their seminal theoretical work, Cox and Blake (1991) note that "genuine commitment" to cultural diversity at the organizational level was crucial to DM success. This sentiment reappears intermittently over the proceeding decades, but to this point, it lacks a consistent conceptualization in the literature. Cox and Blake's (1991) concept of genuineness has more often been conceptualized as an aspect of constructs like authenticity or behavioral integrity, which in turn have been primarily considered at the individual level in the management literature, with only a few notable exceptions applying the construct to organizations (see Cording, Harrison, Hoskisson, \& Jonsen, 2014; Lee \& Yoon, 2018, Smith et al., 2012).

However, in an age when employees are becoming increasingly cynical towards large organizations (Archimi, Reynaud, Yasin, \& Bhatti, 2018), organizational authenticity presents a logical organizational-level construct to explore. It is perhaps even more relevant

\footnotetext{
2 https://www.wired.com/story/googles-employee-diversity-numbers-havent-really-improved/

3 https://www.bbc.co.uk/news/business-44852852

${ }^{4}$ https://www.theguardian.com/media/2017/jul/22/scandal-of-bbc-low-paid-ethnic-minority-staff-creatingas-much-anger-as-sexism
} 
in the context of diversity and inclusion, given the increasing dogma against "political correctness"; most professionals will be able to recall at least one colleague or acquaintance who has stated that their organization's diversity and inclusion programs are exercises in political correctness rather than the moral and/or business-minded endeavors that they are asserted to be (Ely, Meyerson, \& Davidson, 2006). Given the anecdotal prevalence of this cynical thinking, this work proposes that the under-researched construct of organizational authenticity may be a vital antecedent of DM effectiveness.

\section{THEORETICAL BACKGROUND AND HYPOTHESIS DEVELOPMENT}

\section{Perceived Organizational Authenticity}

Cording and colleagues (2014) investigate the construct of organizational authenticity through a social exchange perspective, and define it as, "consistency between a firm's espoused values and its realized practices." Despite the epithetical similarities to the individual-level organizational behavior construct of authentic leadership, organizational authenticity borrows more directly in its development from the individual-level construct of behavioral integrity (Simons, 2002; Simons, Friedman, Liu, \& McLean Parks, 2007). While both authenticity and integrity have been occasionally studied on the organizational level as distinct (though often overlapping) constructs (e.g., Smith et al., 2012), the term "authenticity" is a more semantically-sound descriptor; integrity connotes a broader range of behaviors on the organizational level (i.e., an organization that sells its products to a violent, authoritarian regime, or one that pays its employees very low wages, would be considered to have low "integrity" despite the lack of any inconsistency between its words and actions), which go beyond the definition put forward by Cording et al. (2014). Given this semantic inconsistency, it was necessary to consider works that deal with both behavioral integrity (at the organizational level) and organizational authenticity in reviewing the existing literature. 


\section{Diversity Management Approach as a Moderator of the Demographic Representativeness - Perceived Organizational Authenticity Relationship}

Both diversity management approach and demographic representativeness have been researched extensively in the diversity and inclusion literature. While the closely related construct of diversity climate is most often conceptualized to include employees' behaviors and attitudes as they relate to their perceptions of the organizational diversity and inclusion context (Dwertmann et al., 2016), Olsen and Martins (2012) focused more closely on the steps which organizations take to shift their diversity climates in a desired direction. Those authors define diversity management (DM) approach as, "the explicitly or implicitly held diversity-related values and strategies that underlie [an organizations'] various DM programs, determine which aspects of DM they address, and ultimately affect the diversity-toperformance relationship."

In the relevant diversity climate literature, Dwertmann et al. (2016) build on the work of Ely and Thomas (2001) to propose differentiating between a synergy perspective and a fairness and discrimination perspective, where synergy is focused on realizing the potential performance benefits of diversity while fairness and discrimination is focused on fair treatment, the absence of discrimination, and equal opportunities. This outlook links very closely with Olsen and Martins' (2012) conceptualization of instrumental and terminal values, which are the terms used in this research. Just as in a synergy climate, an organization that takes an instrumental DM approach is one which is focused on leveraging diversity to achieve desirable business outcomes. On the other hand, a terminal DM approach is akin to the fairness and discrimination perspective, in that it views a diverse workforce in and of itself as an independent objective untethered to its primary business goals. 
A review of dozens of large organizations' diversity and inclusion webpages makes it very clear that many firms tend to espouse what those authors describe as an instrumental approach. That is, they generally focus on the importance of diversity to their broader organizational success, rather than as a terminal goal in and of itself. It is unsurprising that organizations would espouse these values, as both Olsen and Martins (2012) and Dwertmann et al. (2016) suggest that these specific "approaches" or "climates" respectively would theoretically be an effective way for organizations to maximize the performance benefits achieved from their diverse workforces.

However, given the rising employee cynicism noted earlier and the ubiquity of this instrumental messaging, one might question what effect (if any) an instrumental DM approach has on key work-related outcomes. This work builds upon previous findings which examined instances in which DM-related words and actions were misaligned (Smith et al., 2012; Windscheid et al., 2016) and integrates this interaction within the DM approach literature. Further, given that demographic variation in and of itself is a key indicator of effective diversity management (Cox \& Blake, 1991; Olsen \& Martins, 2012) and has been shown to be an antecedent of various work-related outcomes in its own right (King, Dawson, West, Gilrane, Peddie, \& Bastin, 2011), demographic representativeness — defined as the degree to which the composition of an organization's employees is representative of the community which it serves - is considered as an independent variable. DM Approach represents an organization's espoused values, while demographic representativeness represents its realized practices.

\section{STUDY 1}

\section{Organizational Authenticity as a Mediator of Diversity Management Effectiveness}


In seeking to understand why perceived organizational authenticity should be viewed as a mediating variable in the context of the relationship between diversity management and employee attitudes, it is necessary to consider the relevant outcomes. Both affective commitment and organizational identification are measured in Study 1, and there is compelling and distinct theoretical support for a direct relationship between perceived organizational authenticity and both variables. Van Knippenberg and Sleebos (2006) explore the differences between these two constructs and conclude that despite partially overlapping, identification and commitment uniquely reflect different aspects of the individual organization relationship. Commitment is fundamentally derived from social exchange theory (Cropanzano \& Mitchell, 2005) and has been the primary conceptualization of the psychological link between person and organization since Meyer and Allen's (1991) seminal work on the subject. Alternatively, identification is inherently self-referential and reflects the psychological merging of the self and the organization (van Knippenberg, 2000). Thus, it is more effectively understood from a social identity perspective (Hogg \& Terry, 2000; Tajfel \& Turner, 1986). Simply put, commitment reflects the psychological relationship between an individual and an organization as separate entities, whereas identification reflects how membership in an organization affects how an individual defines themselves.

In the context of perceived organizational authenticity, both commitment and identification are uniquely valuable as outcome variables. The social exchange perspective has been the dominant framework in research investigating the psychological aspects of the person / organization relationship (Rousseau \& Parks, 1993). On the individual level, research supports the hypothesis that behavioral integrity (i.e., organizational authenticity measured on the individual level) mediates the relationship between authentic leadership and commitment (Leroy et al., 2012; Simons et al., 2007). Central to the social exchange perspective, and by extension to understanding organizational commitment, is the belief the 
organization will trade rewards like pay, support, and recognition for the individual's loyalty and effort (van Knippenberg \& Sleebos, 2006). That belief inherently requires some degree of trust, of which behavioral integrity is an important antecedent (Leroy et al., 2012; Simons, Leroy, Collewaert, \& Masschelein, 2015). As such, it is straightforward to make the case for a direct relationship between organizational authenticity and affective commitment.

It is also uncomplicated to conceptualize a link between organizational authenticity and identification, though from an entirely different theoretical perspective. Again, drawing on research into authentic leadership, identification has been viewed as an essential outcome of authentic leadership since its inception (Avolio \& Gardner, 2005). The social identity perspective posits that individuals derive their self-concepts from the groups — or in this case, the organizations - to which they perceive themselves to belong, and that they are inherently motivated to seek associations which increase their self-esteem and provide distinctiveness over non-members (Dutton, Dukerich, \& Harquail, 1994; Hogg \& Terry, 2000). As Dutton and colleagues (1994) note, individuals value self-integrity and authenticity and, as such, seek out organizations that demonstrate these characteristics. Thus, while there is some overlap between the concepts of commitment and identification, the relationship between organizational authenticity and these variables are explained through different theoretical lenses and offer unique value to understanding diversity management.

In sum, there is some evidence that organizations are perceived as lacking organizational authenticity when their espoused values do not match up with their practices (Lindsey et al., 2017; Smith et al., 2012). An organization's public statements regarding diversity amount to a declaration of the organization's values (Windscheid et al., 2016). If these messages do not match the observed diversity practices (i.e., demographic representativeness), a negative effect on perceptions of authenticity is predicted, which will in turn affect employee attitudes. Given this, the following hypotheses are tested: 
Hypothesis 1: An organization with high demographic representativeness will be perceived as having higher levels of organizational authenticity (1a). This effect will be stronger for women than for men (1b).

Hypothesis 2: Demographic representativeness and DM approach will interact such that an instrumental approach will decrease perceived organizational authenticity in the low DR condition, but not in the high DR condition.

Hypothesis 3a: Perceived Organizational authenticity will mediate the relationship between demographic representativeness and affective commitment

Hypothesis 3b: Perceived Organizational authenticity will mediate the relationship between demographic representativeness and organizational identification.

\section{METHOD}

\section{Sample and Design}

Participants. One hundred and ninety-two university students were recruited using Prolific, an online participant recruitment service. The mean age of the participants was 26.06 years old, and the respondents were $55.7 \%$ male and $43.2 \%$ female. $^{5}$

Procedure. Participants were directed to an online study and told they would have exactly two minutes to review the web pages of a (fictitious) university. The instructions stressed that they would not be able to complete the study without information from these pages to encourage careful examination. A timer automatically kept them on the webpages for exactly two minutes. They then responded to a survey and provided some basic demographic information.

Design and Manipulations. A 2 (DM approach: instrumental vs. terminal) x 2 (demographic representativeness: low vs. high) between-subject design was used for this study. Participants were randomly assigned to one of four possible experimental conditions.

\footnotetext{
${ }^{5}$ Recruitment was limited to respondents who spoke English as a first language to ensure the effectiveness of the language-based manipulation. Of 200 total respondents, one provided incomplete responses, and seven answered attention-check questions incorrectly.
} 
For the first page of the manipulation, participants viewed one of two DM approach conditions (instrumental vs terminal). Demographic representativeness was manipulated on a second webpage that included two pie charts displaying the ethnic and gender composition of the university's faculty (low vs high) (see Figure 1). The percentages were chosen based on roughly the demographics of the large city in which the university was located, and the pie charts were designed and oriented in such a way to make the degree of representativeness readily apparent. In developing the manipulations, an extensive review of real-world diversity websites was conducted and language was taken directly from these examples. Additionally, two diversity experts not involved with this research were consulted as to their realism.

\section{Measures}

For all scales, participants responded using a 7-point Likert scale ranging from $1=$ "Strongly Disagree" to 7 = "Strongly Agree".

Manipulation Checks. To assess the effectiveness of the DR manipulation, participants responded to a two-item scale from Smith et al. (2012) to measure perceived commitment to organizational diversity initiatives. The items were, "To what extent do you think this organization treats its employees fairly?" and "To what extent do you believe that this organization had good intentions in terms of creating a diverse environment?" Participants rated the high-representativeness condition $(M=5.20, S D=1.02)$ significantly higher than the low-representativeness condition $(\mathrm{M}=4.52, \mathrm{SD}=1.27), \mathrm{t}(190)=4.05, \mathrm{p}<$ .001. This measure demonstrates that demographic representativeness is symbolic to participants of a broader organizational commitment to diversity initiatives.

Organizational Identification. Participants' organizational identification was measured using a 5-item scale adapted from Smidts, Pruyn, and Van Riel (2001). An example 
item is "I would feel strong ties with Glenmore University." The scale demonstrated adequate reliability $(\alpha=.93)$.

Affective Commitment. Participants' affective commitment to the fictitious university was measured using a 5-item scale adapted from Meyer and Allen (1991). A sample item is "I really feel as if this organization's problems are my own." The scale demonstrated adequate reliability $(\alpha=.83)$.

Perceived Organizational Authenticity. To assess perceived organizational authenticity, a version of the Simons et al. (2007) Behavioral Integrity scale was adapted to assess an organization. A sample item is “There is a match between the organization's words and actions.” The scale demonstrated adequate reliability $(\alpha=.97)$.

\section{RESULTS}

\section{Results and Analysis}

Hypothesis 1. Hypothesis 1 proposed a direct relationship between demographic representativeness and perceptions of organizational authenticity. An analysis of variance was conducted which showed a significant effect of DR on perceived organizational authenticity with $F(1,189)=57.6, p<.001, \eta 2=.23$. The high DR conditions were rated significantly higher for perceived organizational authenticity $(M=5.33, S D=.99)$ than the low DR conditions $(M=3.96, S D=1.47) t(190)=7.59, p<.001$, supporting Hypothesis 1 a. In assessing Hypothesis $1 \mathrm{~b}$, support was found for the proposed interaction between gender and demography with $F(1,189)=5.38, p=.021, \eta 2=.03$, with women rating perceived organizational authenticity for the low DR condition significantly lower $(M=3.56, S D=$ 1.50) than men $\operatorname{did}(M=4.23, S D=1.40) t(92)=2.21, p=.03$. In contrast, women $(M=$ $5.44, S D=.85)$ and men $(M=5.26, S D=1.11)$ did not rate perceived organizational authenticity significantly differently in the high DR conditions $t(94)=-.85, p=.40$. 
Hypothesis 2. To test the proposed interaction between DM approach and demographic representativeness on perceived organizational authenticity, an analysis of variance was conducted and discovered significant support for the proposed interaction with $F(1,191)=7.29, p=.008, \eta 2=.37$. This moved in the predicted direction as well, as in the two low DR conditions, the terminal DM approach $(M=4.29, S D=1.29)$ resulted in a significantly higher on authenticity than the instrumental DM approach $(M=3.60, S D=$ 1.59) with $t(93)=2.34 . p=.02$ (see Table 2). DM approach did not result in a significant difference in the two high DR conditions. Post-hoc analysis using the Sidak (1967) adjustment also supported the existence of a significant difference between instrumental and terminal DM approach values in the low DR conditions 95\% CIs [.02, 1.37]. These findings supported the interaction predicted in Hypothesis 2. See Table 1 for intercorrelations, means, and standard deviations for all study variables.

Insert Table 1 Here

Hypotheses 3. Hypothesis 3 predicted that perceived organizational authenticity would mediate the relationship between DR and both organizational identification and affective commitment, in addition to DM approach and participant gender moderating the DR $\rightarrow$ perceived organizational authenticity relationship. To test this, moderated mediation analysis was conducted using a bootstrapping confidence interval (CI), which is supported as a useful inferential tool (Hayes, 2018) and a strong alternative to p-values (Halsey, CurranEverett, Vowler, \& Drummond, 2015). Using Model 9 within the PROCESS macro ${ }^{6}$, the

\footnotetext{
${ }^{6}$ These results were compared against other models in the PROCESS macro, including Model 11 for three-way moderated mediation, Model 7 for moderated mediation with either DM approach or gender, and model 4 for simple mediation. The model seen in Figure 3.7 proved to be the best fit for the data. Further, no significant interactions were detected on the path from DR to identification / commitment or on the path from perceived organizational authenticity to identification / commitment, further supporting this model.
} 
proposed model was supported. The analysis revealed support for the hypothesized moderated mediation model, with both DM approach $B=.481,95 \% C I[.11, .86]$ and Gender $B=-.412,95 \% C I[-.79,-.05]$ resulting in significant indices of moderated mediation with organizational identification as an outcome variable. The results followed the same pattern for affective commitment, with both DM approach $B=.40,95 \%[.10, .73]$ and gender $B=-$ $.34,95 \% C I[-.66,-.04]$ again reaching significant indices of moderated mediation.

Insert Table 2 Here

\section{STUDIES 2 AND 3}

Building on the findings of Study 1, the aim of these studies was to experimentally test a practical, applied intervention focused on increasing employee perceptions of organizational authenticity. Study 1 demonstrated that these perceptions may explain the relationship between diversity management and employee attitudes. In particular, the results showed evidence of a backlash effect when an organization's observed practices did not match its espoused diversity values. In light of these findings, an organizational messaging intervention based on signaling theory and social psychology research on hypocrisy was developed and tested in both a higher education (Study 2) and a corporate (Study 3) context.

\section{A Two-Sided Messaging Intervention to Increase Perceived Organizational Authenticity}

In Study 1, the results demonstrated that there may be a backlash effect against organizations who espouse certain diversity values when their observed practices do not match that messaging. Building on that and drawing from signaling theory, Studies 2 and 3 test a messaging intervention to negate that backlash and increase employee perceptions of organizational authenticity. Developed originally in evolutionary biology, researchers have also previously applied signaling theory to organizational psychology (e.g., Lindsey et al., 
2017; Rynes \& Rosen, 1995; Turban \& Greening, 1996) and economics (e.g., Bergh et al., 2014; Spence, 1973). In essence, in this context it posits that organizational attributes serve as "signals" to individuals, which in turn allows them to make judgements about the organization's unobservable characteristics (Turban \& Greening, 1996). For example, in Study 1 it is noted that the demographic composition of a company's employees (observable) is a signal about the degree to which their diversity management practices are effective (unobservable).

In its effect, this is not entirely dissimilar (and perhaps complimentary) to the similarity / attraction paradigm (Byrne, 1971) and social identity theory (Tajfel \& Turner, 1979) in an organizational context. Diversity and inclusion initiatives signal that an organization has certain values and norms with regard to diversity. As O'Reilly and Chatman (1986) note, people are attracted to organizations that they believe to have values and norms that they deem important. Similarly, central to social identity theory is that individuals classify themselves into social categories based in part on how that categorization reflects back on their self-concept (Ashforth \& Mael, 1989), which in turn drives them to seek out groups to which membership will reflect positively on themselves (Hogg \& Terry, 2000).

A primary contribution of this research is an investigation of the potential negative effects for organizations that do not 'practice what they preach' when it comes to diversity. This evokes the idea of hypocrisy, more commonly researched from a social psychology perspective. In general, it is accepted that hypocrisy is viewed as a negative behavior, yet the approach to studying how people perceive hypocrisy has been mixed (Jordan et al., 2017). Some researchers approach the topic as a difference between what individuals view as normative and how they actually behave (e.g., Wagner, Lutz, \& Weitz, 2009) while others approach it as the discrepancy between what individuals believe others should do in a given situation versus what they would do themselves (e.g., Valdesolo \& DeSteno, 2008). In this 
context, the former is the primary focus, as it is most relevant to Simons' (2002)

conceptualization of behavioral integrity (i.e., organizational authenticity), which he argues is inextricably linked to hypocrisy.

There are multiple lines of reasoning by why hypocrisy could have negative outcomes from an organizational standpoint. One straightforward explanation for the negative effects is that misleading people is generally regarded as morally wrong (Jordan et al., 2017).

Alternatively, organizational hypocrisy could be viewed as 'free-riding' if the organization were to gain something of value from their statements (e.g., reputation, recruits, clients) without actually absorbing the cost of the behavior (DeNisi, Randolph, \& Blencoe, 1983).

Crucially, the extent to which people feel negatively toward hypocrites (or in this case, hypocritical organizations) cannot be explained by their transgressions alone; hypocrisy has a negative effect above and beyond the transgression itself. Jordan et al. (2017) make a compelling case for what they describe as a false-signaling theory of hypocrisy; they experimentally demonstrate that when an individual observes hypocritical behavior, it is the act of 'false signaling' that elicits negative reactions rather than the transgression itself. If one accepts that organizational hypocrisy can have negative impacts above and beyond the transgression itself, one must consider what signals are taken into account when individuals judge whether an organization is acting hypocritically. Because organizational messaging in this context serves in essence as an advertisement for the organization's values, the marketing literature is considered in developing a potential intervention. In particular, research focused on corporate social responsibility (e.g., Lee \& Yoon, 2018; Turban \& Greening, 1997) and two-sided messaging (e.g., Crowley \& Hoyer, 1994; Pechmann, 1992) is reviewed.

Two-sided messaging has been a focus of research (mostly in marketing, consumer, and communication research) for decades (Crowley \& Hoyer, 1994). This is defined as when 
both positive and negative attributes of a product, idea, or topic are presented, often in the service of persuasion (Eisend, 2006). For example, a car salesperson might acknowledge that the Ford Fiesta he or she is selling is unlikely to outrun a Ferrari while making the case that the Ford is the better option overall because it is safe and economical. Evidence in the marketing literature suggests that messages that include some negative information about a product or service can be more effective than if no negative information is presented (Pechmann, 1992). Further, in addition to potentially strengthening the message against counterarguments by discussing a limitation of the advertised product or service, the brand also increases its credibility with the potential costumer (Kamins, Brand, Stuart, \& Moe, 1989). This marketing research is relevant, as an organization's messaging can be viewed as a de facto advertisement for the organization; in this context, advertisements for their diversity and inclusion practices specifically.

However, despite the support for two-sided messaging in the literature, a review of diversity and inclusion web pages noted very few examples of its use. One notable exception is Google, who write in the conclusion of their Annual Diversity Report", "Our results in diversity, equity, and inclusion don't yet match our ambitions." This is a quintessential example of two-sided messaging. The organization is implicitly arguing that they are dedicated to DM practices that would benefit both the organization and its employees, but in doing so, they acknowledge a likely critique of that argument with the intent of making their point more convincingly.

As such, for Studies 2 and 3, a practical and realistic two-sided messaging intervention was developed that lends itself to experimental testing and could be readily

\footnotetext{
${ }^{7}$ https://diversity.google/annual-report/
} 
applied in a real-world organization. Both experiments consisted of two conditions: hypocritical and honest hypocrite. To most directly extend the findings of the previous studies, the hypocritical condition was identical to the instrumental - low DR condition in Study 1, while the honest hypocrite condition includes one additional sentence acknowledging the organization's lack of success with diversity management. Two identical hypotheses were tested for both experiments:

Hypothesis 1: Including a two-sided argument (i.e., honest hypocrite) with a hypocritical organization will result in higher ratings of perceived organizational authenticity than for an identical organizational with no two-sided argument

Hypothesis 2: Perceived organizational authenticity will mediate (in parallel) the positive relationship between a two-sided argument and organizational identification (2a) and affective commitment ( $2 b)$

\section{STUDY 2}

\section{Sample and Design}

Participants. Ninety-one participants were recruited using Prolific. All were 18 or older and were prescreened for their status as students to increase the salience of the university manipulation. Three attention check questions were included, regarding the name of the fictitious university, the proportion of male to female staff, and whether or not their condition contained the relevant two-sided message. They included 52 women $(57.1 \%)$ and 39 men $(42.9 \%)$ with an average age of $25.37(S D=7.9)$. Participants were compensated an average of $£ 11.25 / \mathrm{hr}$.

Procedure. The procedure was similar to that of the previous study. Participants viewed one of two conditions for exactly two minutes, prior to which they were told that it was essential that they read the two web pages carefully.

Design and Manipulations. Participants were randomly assigned to one of two conditions: hypocrite or honest hypocrite (i.e., two-sided message). The hypocrite condition 
was identical to the low DR - instrumental condition from the previous study. In other words, an organization whose espoused values do not match its realized practices. The only change made between that and the honest hypocrite condition was the addition of the sentence, "We are open in acknowledging that our faculty and staff are not yet as diverse as we would like."

Measures. The same scales used in Study 1 were used to measure perceived organizational authenticity $(\alpha=.96)$, affective commitment $(\alpha=.75)$, and organizational identification $(\alpha=.91)$. All were found to have acceptable reliability.

\section{RESULTS}

Independent sample $t$-tests were conducted to test the effects of the honest hypocrite condition on perceived organizational authenticity. Means, standard deviations, and correlations for all measures are presented in Table 3. Results revealed a significant effect $t(89)=2.43, p=.02, d=.51$ in the predicted direction, with perceived organizational authenticity rated lower in the hypocritical condition $(M=3.22, S D=1.39)$ than in the honest hypocrite condition $(M=3.87, S D=1.14)$, supporting Hypothesis 1 .

Insert Table 3 Here

Mediation analysis (Hayes, 2018 PROCESS macro, model 4) was conducted to test whether perceived organizational authenticity would mediate the relationship between the hypocritical - honest hypocrite conditions and affective commitment / organizational identification. Perceived organizational authenticity mediated the relationship between the hypocritical - honest hypocrite conditions and affective commitment $B=.23, S E=.10,95 \%$ 
$C I[-.44,-.04]$ and organizational identification $B=.27, S E=.12,95 \% C I[-.52,-.05]$, supporting both Hypothesis $2 \mathrm{a}$ and $2 \mathrm{~b}$.

\section{STUDY 3}

\section{Sample and Design}

Participants. One hundred and seventy-five participants were recruited using Prolific. All were 18 or older and were prescreened for their status as non-student professionals to increase the salience of the corporate diversity manipulation. These included 62 men $(35.4 \%)$ and 113 women $(64.6 \%)$ with an average age of $35.13(S D=10.06)$.

Procedure. The procedure, design, and manipulations were identical to those of Study 2, except that the manipulations were altered to reflect a fictional business rather than a university. ${ }^{8}$

Measures. The measures were identical to those in Study 2. The scales for perceived organizational authenticity $(\alpha=.96)$, affective commitment $(\alpha=.79)$, and organizational identification $(\alpha=.92)$ were all found to have adequate reliability.

\section{RESULTS}

Just as in Study 2, the results showed a significant effect of the honest hypocrite condition on perceived organizational authenticity, supporting the effectiveness of the hypothesized two-sided messaging intervention $t(173)=4.11, p<.001, d=.62$. The honest hypocrite condition resulted in significantly higher ratings of perceived organizational authenticity $(M=3.53, S D=1.24$ versus $M=2.76, S D=1.25)$, supporting Hypothesis 1 .

\footnotetext{
${ }^{8}$ The name Waypoint Corporation was chosen as it was a realistic name that was not associated with any wellknown real-world organizations. The language was altered slightly to reflect a corporate rather than university web page (e.g., "enabling our employees" rather than "enabling our students").
} 
Insert Table 4 Here

Using the PROCESS macro (Hayes, 2018), the hypothesized mediation model was also supported, with perceived organizational authenticity explaining the relationship between the hypocritical / honest hypocrite conditions and both affective commitment $(B=$ $.38, S E=.11,95 \% C I[.18, .60]$ and organizational identification $(B=.47, S E=.13,95 \% C I$ $[.24, .73]$. This fully supported Hypothesis 2 . As in Study 1, perceived organizational authenticity mediated the relationship between the diversity management independent variable and the dependent variables, with the direct effect no longer significant for both affective commitment $t(173)=.88, p=.38$ and organizational identification $t(173)=.95, p=$ .34 .

\section{STUDY 4}

The Espoused - Practiced DM Discrepancy Measure and Turnover Intentions as an Outcome Variable

In Study 1, the experimental results indicated that a discrepancy between an organization's espoused diversity management (DM) approach values and its realized DM practices has additional explanatory power beyond the realized practices themselves. As such, the next step was to explore that finding in a real-world context. Several reviews and meta-analyses have considered the outcomes of diversity in organizations (e.g., Guillaume et al., 2014; Jackson \& Joshi, 2011; van Knippenberg \& Schippers, 2007), and they consistently conclude that these outcomes are equivocal and difficult to reliably predict. One potential explanation is that much of this research focuses on the main effects of some specific diversity management practice (e.g., Homan et al., Rynes \& Rosen 1995). It is only recently that a new stream of research has emerged which considers employees' overall perceptions of 
these practices more generally and which antecedents may affect those perceptions (OtayeEbede, 2016).

Nishii et al. (2018) note the importance of distinguishing between espoused and enacted DM policies and practices. Further, those authors specifically recognize authenticity as a key factor that influences how employees perceive DM practices overall. Various organizational cues might shape employees' judgments of DM practices. For example, Bezrukova et al. (2016) note that diversity training implemented as a standalone initiative may be seen as less credible than a broader, organization-wide effort that includes various consistent initiatives. Importantly, employee reactions to a diversity policy or practice depends on its alignment with what is actually enacted by managers (Simons, 2002). There is also an extensive literature suggesting that employee reactions to a diversity training initiative are more positive when it is supported by company leaders (Kulik \& Roberson, 2008; Rynes \& Rosen, 1995). For example, Ragins and Cornwell (2001) found that whether or not an employee's same-sex partner was invited to company social events was a more important predictor of employee perceptions than any existent policies aimed at supporting gay-lesbianbisexual employees. This is indirect evidence to the importance that authenticity may have in determining reactions to DM programs.

The challenge inherent in applying this framework to the field is finding a measure which can assess the mismatch between words and actions that was manipulated in the experimental studies. In a 2018 review, Otaye-Ebede (2018) notes 17 previously published scales used to measure some aspect of DM or DM practices, though the author notes that most were not psychometrically validated. Scales for diversity climate are relevant as well but tend to focus more on employee perceptions of the outcomes of DM (rather than the practices themselves), which limits their practical relevance and informational value (Dwertmann et al., 2016; McKay, Avery, Tonidandel, Morris, Hernandez, \& Hebl, 2007). 
Given this, I focus on the Employee Perceptions of Diversity Management Practices (EPDMP) scale developed by Otaye-Ebede (2018), as it focuses on the DM practices employed by an organization rather than measuring the attitudinal outcome those practices have on employees (i.e., diversity climate). To assess authenticity in diversity management (Cording et al., 2014; Nishii et al., 2018), a novel "espoused - practiced DM discrepancy" measure is developed based on Otaye-Ebede's (2018) EPDMP scale. Specifically, participants will respond to each item of the EPDMP scale based on what their organization "says" it does (espoused) and what it "actually" does (practiced). Similar discrepancy measure scales have been used previously in the literature (e.g., Turner \& Crisp, 2010).

In addition to this novel espoused - practiced DM discrepancy measure, turnover intentions will also be measured to extend the practical relevance of the Study 1 and replicate previous research linking turnover intentions with work attitudes like commitment (Meyer et al., 2002; O’Reilly \& Chatman, 1986) and organizational identification (Van Dick et al., 2004; Van Knippenberg \& Sleebos, 2006).

Numerous studies show that diversity climate has a negative relationship on turnover intentions (e.g., McKay et al., 2007), such that a positive diversity climate decreases turnover intentions among employees. Further, the literature demonstrates a link between diversity climate and organizational commitment from a social exchange perspective (e.g., Kooij et al., 2010) as well as organizational identification from a social identity perspective (e.g., Van Knippenberg et al., 2007). Given that both organizational commitment (e.g., Tett \& Meyer, 1993) and organizational identification (e.g., Abrams, Ando, \& Hinkle, 1998; Mael \& Ashforth, 1995; Van Dick et al., 2004) are well-established proximal predictors of turnover intentions, it seems relevant to measure and control for diversity climate. Crucially, this will establish whether the espoused - practiced DM discrepancy has predictive power above and beyond diversity climate in regard to turnover intentions. 
Based on the emerging area of organizational authenticity discussed previously (e.g., Cording et al., 2014, Nishii et al., 2018; Windscheid et al., 2016), and given the experimental evidence from Study 1, Study 4 hypothesizes that espoused - practiced DM discrepancy should be negatively related to perceived organizational authenticity (Hypothesis 1). Further, it is predicted that perceived organizational authenticity will be positively related to both affective commitment (Hypothesis 2a) and organizational identification (Hypothesis 2b). I also predict that both affective commitment and organizational identification will be negatively related to turnover intentions (Hypotheses 3a and 3b). Finally, a serial mediation model building on the experimental findings from the previous chapters is tested in which the positive relationship between espoused - practiced DM discrepancy and turnover intentions is sequentially mediated by perceived organizational authenticity and affective commitment (4a) / organizational identification (4b) (in parallel) when controlling for diversity climate, age, tenure, and size of the organization.

\section{STUDY 4}

\section{Sample and Design}

Participants. Two hundred participants $(N=200)$ were recruited from organizations in the United Kingdom (84\%) and the United States (16\%) using Prolific. Participants were compensated at an average rate of $£ 8.40$ per hour. All participants self-identified as currently employed and as being non-students, were between the ages of 18-65 $(M=38.49, S D=$ 10.26), and were $62 \%$ female ( $37 \%$ male, $1 \%$ other).

Data was collected about the size of the organization for which they worked and their tenure at that organization. Tenure was evenly distributed, with $50 \%$ indicating less than 5 years (13.5\% less than one year, 16\% 1-2 years, 20.5\% 3-5 years) and 50\% indicating more than five years with their organization (25.5\% 5-10 years, 24.5\% 10+ years). Organization 
size was fairly evenly distributed as well, with $4.5 \%$ of respondents at an organization with less than ten employees, $12.5 \%$ 10-100, $11.5 \%$ 100-250, 20.5\% 250-1000, 25.5\% 100010,000 , and $25.5 \% 10,000$ or more.

Procedure. Participants were directed to a survey where they were told they would be asked questions about the organization for which they currently worked. They were given explicit instruction about the employee perceptions of diversity management practices (EPDMP) claim-actual discrepancy scale. The instructions read, "We are interested in determining if there is a difference between what organizations say and what they actually do when it comes to diversity and inclusion practices", and clarified that what an "organization says" might include "marketing, websites, emails, policy documents, or statements from leaders within your organization."

\section{Measures}

EPDMP (Communicated - Observed Discrepancy). Based on the items from the EPDMP scale (Otaye-Ebede, 2018), a "says versus does" discrepancy measure was created by creating a difference score (e.g., Turner \& Crisp, 2010). For each item, participants were first asked whether their organization "says it does this" and then whether their organization "actually does this". An example item is, "My organization spends money and time on diversity awareness and related training." Participants responded on a seven-point Likert scale ranging from $1=$ "Not at all" to 7 = "To a very large extent".

For each item, a discrepancy score was calculated by taking the difference between the participants responses to the "says" vs "actually does" version of each item. Based on these discrepancy scores, the overall scale demonstrated high reliability $(\alpha=.86)$.

Diversity Climate. Diversity climate was measured using a 7-item scale from McKay et al. (2007). An example item is, "I feel that my organization recruits from diverse sources." 
Turnover Intentions. Turnover intentions were measured with a 2-item scale from Vandenberghe and Bentein (2010) $(\alpha=.88)$. An example item is "I often think about quitting my current organization."

Other Measures. The same scales as used in the previous studies were used to measure perceived organizational authenticity $(\alpha=.96)$, organizational identification $(\alpha=$ .93), and affective commitment $(\alpha=.91)$.

\section{RESULTS}

In the analysis for Study 4, age, tenure, organization size, and diversity climate were included in the final regression analysis as covariates. ${ }^{9}$ Means, standard deviations, and correlations are presented in Table 5.

Hypothesis 1. Hypothesis 1 stated that espoused - practiced DM discrepancy would be negatively related to perceived organizational authenticity. Regression analysis found the predicted negative association between discrepancy and organizational authenticity, $B=-.73$, $S E=.09, t(193)=-4.32, p<.001$, offering full support for Hypothesis 1. In other words, as the discrepancy between what the organization says and what it does regarding diversity increases, employee perceptions of organizational authenticity decrease.

Hypothesis 2. Hypothesis 2 predicted that perceived organizational authenticity would be positively related to both affective commitment and organizational identification. Linear regression analysis provided support for both Hypothesis $2 \mathrm{a}$ and $2 \mathrm{~b}$, with perceived

\footnotetext{
${ }^{9}$ A meta-analysis from Cohen (1993) notes that both age and tenure relate to organizational commitment in unique ways, hence why they are both included. Organization size has also been previously linked to identification processes (Mignonac, Herbach, \& Guerrero, 2006), and both of those attitudes have been extensively linked to turnover intentions as discussed previously. All four are commonly statistically controlled for in organizational research (Bernerth, Cole, Taylor, \& Walker, 2018). The extensive links between diversity climate and job attitudes and outcomes are also discussed in the previous section of this chapter.
} 
organizational authenticity predicting affective commitment $B=.39, S E=.10, t(193)=3.97$, $p<.001$ and organizational identification $B=.40, S E=.09 t(193)=4.56, p<.001$.

Insert Table 5 Here

Hypothesis 3. Hypothesis 3 predicted that both affective commitment (3a) and organizational identification ( $3 b$ ) would be negatively related to turnover intentions. Affective commitment significantly predicted turnover intentions $B=-.87, S E=.08, t(192)=-11.17, p<.001$ supporting Hypothesis 3a, while organizational identification similarly predicted turnover intentions $B=-.99, S E=.09, t(192)=-11.55, p<.001$ supporting Hypothesis $3 b$.

Hypothesis 4. Two serial mediation analyses were conducted to test Hypothesis 4 (see Figure 2). These analyses allowed me to test a model in which authenticity and either organizational identification (model 1) or affective commitment (model 2) predict turnover intentions in sequence ${ }^{10}$. In the first analysis, results showed that perceived organizational authenticity and then affective commitment sequentially mediated the effect of espoused - practiced DM discrepancy on turnover intentions, with an overall indirect effect of $B=.25, S E=.07,95 \%$ $C I[.12, .39]$. The direct effect of the espoused - practiced discrepancy on affective commitment $B=.43, S E=.17, t(195)=2.59, p=.01$ became non-significant in the serial mediation model $B=.15, S E=.15, t(195)=1.04, p=.30$.

Similarly, in the second analysis, the results showed the perceived organizational authenticity and then organizational identification sequentially mediated the effect of espoused - practiced DM discrepancy on turnover intentions $B=.29, S E=.07,95 \% C I[.15$,

10. The full conceptual model was tested with two separate analyses because the PROCESS Macro (Hayes, 2018) does not allow two mediators in parallel (i.e. affective commitment and organizational identification) while testing for a mediation in sequence. 
.44]. The significant total effect of the espoused - practiced DM discrepancy on organizational identification $B=.43, S E=.17, t(195)=2.6, p=.01$ also became nonsignificant in the direct path $B=.16, S E=.15, t(195)=1.11, p=.27$. These results are nearly identical, reflecting the high correlation between affective commitment and organizational identification.

Insert Figure 2 Here

Both of these models were compared to alternative mediation models with either one but not both of the mediating variables included using the alternate pathways provided by PROCESS. For affective commitment, these were $B=.03, S E=.09,95 \% C I[-.15, .20]$ for perceived organizational authenticity as the mediator and $B=-.05, S E=.13,95 \% C I[-.32$, .20] with only affective commitment as the mediator. For organizational identification, the alternative models were $B=.07, \mathrm{SE}=.09,95 \% C I[-.11, .24]$ for perceived organizational authenticity as the sole mediator and $B=-.04, S E=.12,95 \% C I[-.28, .20]$ with organizational identification. ${ }^{11}$ The confidence intervals for all four potential alternative simple mediation models included zero, which supports our prediction that our serial mediation is a most robust model. These results fully support Hypothesis 4 .

\section{DISCUSSION}

"Practice what you preach", "walk the walk", and various other idiomatic platitudes of similar sentiment are commonplace in organizational research and practice. Thus, the

\footnotetext{
${ }^{11}$ Analyses in which the order of the three predictors was alternated were also conducted (e.g., identification -> discrepancy -> authenticity -> turnover intentions, etc). For all possible combinations, the confidence intervals included zero, further supporting the hypothesized order of mediation. I do note that a fully reversed model (i.e., Turnover intentions -> Org ID -> authenticity -> discrepancy) was supported with an indirect effect of $B=.04$, $S E=.02,95 \% C I[.01, .08]$. However, this is a much smaller effect, and the hypothesized model is decidedly more in line with theory and the experimental findings presented in the previous chapter.
} 
recent emergence of "authenticity" as a focus in the diversity management literature is apropos (Nishii et al., 2018). In brief, this research offers several significant contributions to the literature. Firstly, this research integrates organizational authenticity with the diversity climate literature, and in doing so, establishes and empirically supports a theoretical framework for this relationship. In providing a theoretical rationale and empirical support for the mediating role of organizational authenticity in a diversity management context, this work opens a much-needed avenue for future research on DM efficacy. Second, to our knowledge, this is the only study to date to empirically investigate the relationship between organizational authenticity and organizational commitment / identification. Finally, the findings provide valuable insight into the effects of the interaction between demographic representativeness and diversity management approach. In this especially, this work provides novel and indispensable guidance to organizations seeking to increase the diversity of their workforces while avoiding unintended consequences.

These findings offer a potential explanation to why organizations struggle to design and implement effective diversity management practices and training (Bezrukova et al., 2016; Kalev et al., 2006). It is conceivable that if the organizations that struggle the most with diversity and inclusion to begin with undertake all the recommended best practices and truly strive to develop a synergistic climate, any perceived lack of authenticity could mitigate the potential achievements. This results in an unfortunate catch-22, as the organizations that need to improve their DM the most, often as the result of decades of poor practices and/or neglect, may face the biggest hurdles convincing their employees of their sincerity.

Study 1 also offers a significant contribution in this area by synthesizing findings from a variety of tangentially related studies on authenticity, diversity climate, and commitment, and producing a holistic, parsimonious model which incorporates the underresearched construct of perceived authenticity on the organizational level. It incorporates 
work on organizational authenticity from the marketing and broader management literature into the organization behavior context (Cording et al, 2014; Lee \& Yoon, 2018), draws on leadership research into authenticity in developing the construct (Gardner et al., 2011; Leroy et al, 2012), and develops a connection to practically relevant outcome variables.

Organizational-level authenticity is established as a construct which can be measured by assessing employee perceptions, which has only been attempted once previously (see Smith et al., 2012). Given the well-established importance of authenticity (and behavioral integrity) as an individual-level construct (Simons et al., 2015), applying it to the organizational level is a logical and important path forward in diversity management research.

The findings of Study 1 support the notion that no matter how well-meaning a diversity management policy or practice may be, it may not have the desired effects if employees do not believe that it is authentic. Given this, Studies 2 and 3 offer a significant contribution to research and practice by developing and testing an intervention that organizations could use to overcome this cynicism toward diversity and inclusion practices. The results offer compelling evidence that this theoretically robust intervention will have the predicted, desirable effects on employee attitudes.

In line with the hypotheses and the findings of Jordan et al. (2017), the honest hypocrite condition led to higher levels of perceived organizational authenticity than the hypocritical condition. Building on the hypocrisy literature, it is clear that the false signal espousing an instrumental DM approach value for diversity while not being demographically representative - results in more negative reactions than just the transgression of not being demographically diverse in and of itself. Further, as Jordan et al. (2017) found with individuals, an organization acknowledging that it was sometimes guilty of that transgression was enough to limit the negative effects. This also aligns with marketing research on twosided messaging, which has shown that presenting some negative aspect of a product or 
services (or in this case, an organization), in addition to the positive aspects, can be more persuasive (Crowley \& Hoyer, 1994; Eisend, 2006). By acknowledging that it has not yet fully achieved its diversity goals, the organization is more successful in persuading its employees that it sincerely values diversity, which in turn affects their work-related attitudes.

Study 4 add considerable external validity to this research, and is the first study to directly measure the discrepancy between espoused values and realized diversity management practices in real-world organizations. In empirically supporting the explanatory value of this measure - and crucially, that it has explanatory power above and beyond that of diversity climate - Study 4 makes a substantial contribution to the diversity management literature in its own right. Study 4 also significantly extends the findings of the first three experimental studies by including a work-outcome measure (turnover intentions) in a survey of current employees about their own organization. This is a particularly valuable contribution, as turnover (and by extension, turnover intentions) is one of the most challenging and costly issues organizations face (Douglas \& Leite, 2017). Study 4 also adds further support to the already-substantial body of research linking affective commitment and organizational identification to turnover intentions (e.g. Meyer et al., 2002).

\section{Practical Implications}

This research offers clear evidence that perceived inauthenticity may explain why DM programs often struggle to achieve their goals. Organizations interested not only in leveraging diversity for business outcomes, but also in creating a more equal and positive work environment for non-majority employees, should consider perceptions of authenticity in every diversity and inclusion policy and practice.

Specifically, Studies 2 and 3 answer Windscheid and colleagues' (2016) call by offering a clear, practical step organizations can take to better convey their authenticity to 
employees. No matter how sincere an organization's motives, decades of inequality has left employees cynical toward diversity and inclusion. The intervention tested in Studies 2 and 3 offers a simple, yet theoretically grounded solution for organizations. The manipulation presented a company that was not yet very diverse but expressed a genuine commitment to valuing diversity; this could be any of thousands of companies around the world. As such, the finding that one additional sentence had a large effect on perceived authenticity, which in turn increased commitment and identification, has clear practical relevance. Organizations that can relate to the description above should consider immediately including similar twosided messages on their website and other internal and external communications. ${ }^{12}$

Finally, organizations should not discount the consistently large positive effect that demographic representativeness has on commitment, identification, and perceptions of organizational authenticity. The best advice one can give to an organization regarding diversity is to "walk the walk". Countless studies (e.g., Harjoto et al., 2015; Lindsey et al., 2017; Miller \& Triana, 2009; Windscheid et al., 2016), including this one, have demonstrated that the observable demographic diversity of employees is an important signal to those inside and outside the organization. Organizations should relentlessly strive to recruit from diverse sources, ensure top managers and board members are diverse, and ensure women, LGBT individuals, and other minority groups have specific career development and planned progression programs available to them.

\footnotetext{
12 A cynic might criticize this research as offering a tool for disingenuous organizations to "trick" their employees into believing their diversity efforts are in good faith. While a valid concern, it is difficult to see the downside from a utilitarian perspective. If perceived authenticity is necessary for diversity management to be successful, and one of the goals of diversity management is to improve the well being of diverse employees, then those employees still stand to benefit regardless of the organization's true motives. Further, we know that effective diversity management can signal employer attractiveness (Windscheid et al., 2016), so it could also lead to more job opportunities for diverse individuals. Additionally, contact theory (Pettigrew \& Tropp, 2006) tells us that intergroup contact can reduce prejudice between groups. As such, even if an organization's motives were not sincere to start, increased employee diversity could decrease intergroup prejudice over time.
} 


\section{Limitations and Future Avenues for Research}

The findings presented herein are not without limitations, which also serve to highlight several potential avenues for future research. Of note, common rater effect weakens any causal claims regarding mediation (Antonakis, Bendahan, Jacquart, \& Lalive, 2010) because the mediating and dependent variables were collected from the same source. However, the fact that similar mediation effects were observed across three different samples alleviates these concerns to some degree. External validity is generally sacrificed at the expense of internal validity in experimental research (Podsakoff \& Podsakoff, 2019). While the field survey in Study 4 does serve to enhance external validity, future research should conduct controlled field experiments or multilevel surveys within a single organization.

Because this research used primarily self-report measures, social desirability bias is a concern (i.e., participants responding in a pro-diversity manner because they feel that it is the socially desirable response). It is possible that an implicit measure (such as an implicitassociation test) could be used in future research. Additionally, objective measures of commitment and/or performance (e.g., turnover, sales performance) would be ideal.

The novel usage of signaling theory and two-sided messaging in an employee-focused intervention should be researched more broadly in organizations. Further research should also explore whether leaders can be trained to deliver similar two-sided messages and whether they would have a similar positive effect on employee attitudes. A longitudinal, field experiment at the unit level in an organization would be an ideal methodology to test such an intervention, which may well be a very effective way to improve diversity management outcomes in practice.

Finally, perceived organizational authenticity is an underexplored construct more broadly in management research. This adds to the growing body of work that positions it as 
an important explanatory variable in organizational settings (e.g., Leroy et al., 2012; Lindsey et al., 2017; Windscheid et al., 2016). Lehman et al. (2019) open their recent review of authenticity in management research bluntly, with the statement, "Authenticity is in high demand." The adaptation of behavioral integrity to the organizational level and integration with Cording and colleagues' (2014) framework offers a useful approach for future organizational research on varied topics. In addition to diversity management, this approach could be beneficial in the study of climate and culture more broadly, organizational change, talent management, and generally any organization-level action that may be perceived as either authentic or inauthentic by employees.

\section{Conclusion}

This research sought to address the pressing issue of diversity management effectiveness by focusing on two critical gaps in the literature: (1) What combination of diversity management values and practices results in undesirable attitudinal reactions among employees, and (2) What is the underlying mechanism that explains this relationship? Across three experimental studies and one field study, the results demonstrated compelling evidence that perceived organizational authenticity explained the relationship between organizational diversity practices and relevant employee attitudes. If organizations approach diversity management as a tool to achieve both better business outcomes and better personal outcomes for their diverse employees, these findings show that consistency between their espoused values and realized practices — organizational authenticity — should be of primary concern. In sum, this research offers organizations and researchers alike a compelling new direction from which to approach diversity management. 


\section{REFERENCES}

Allen, N. J., \& Meyer, J. P. (1990). The measurement and antecedents of affective, continuance and normative commitment to the organization. Journal of Occupational Psychology, 63(1), 1-18. https://doi.org/10.1111/j.2044-8325.1990.tb00506.x

Antonakis, J., Bendahan, S., Jacquart, P., \& Lalive, R. (2010). On making causal claims: A review and recommendations. The Leadership Quarterly, 21(6), 1086-1120. https://doi.org/10.1016/j.leaqua.2010.10.010

Archimi, C. S., Reynaud, E., Yasin, H. M., \& Bhatti, Z. A. (2018). How perceived corporate social responsibility affects employee cynicism: The mediating role of organizational trust. Journal of Business Ethics, 1-15. https://doi.org/10.1007/s10551-018-3882-6

Avery, D. R., McKay, P. F., \& Volpone, S. D. (2012). Diversity Staffing: Inclusive Personnel Recruitment and Selection Practices. The Oxford Handbook of Diversity and Work, (pp. 282-299). New York, NY: Oxford University Press.

Avolio, B. J., \& Gardner, W. L. (2005). Authentic leadership development: Getting to the root of positive forms of leadership. The Leadership Quarterly, 16(3), 315-338. https://doi.org/10.1016/j.leaqua.2005.03.001

Banks, G. C., McCauley, K. D., Gardner, W. L., \& Guler, C. E. (2016). A meta-analytic review of authentic and transformational leadership: A test for redundancy. The Leadership Quarterly, 27(4), 634-652. . https://doi.org/10.1177/0149206316665461

Bergh, D. D., Connelly, B. L., Ketchen Jr, D. J., \& Shannon, L. M. (2014). Signalling theory and equilibrium in strategic management research: An assessment and a research agenda. Journal of Management Studies, 51(8), 1334-1360. https://doi.org/10.1111/joms.12097

Bernerth, J. B., Cole, M. S., Taylor, E. C., \& Walker, H. J. (2018). Control variables in leadership research: A qualitative and quantitative review. Journal of Management, 44(1), 131-160. https://doi.org/10.1177/0149206317690586

Bezrukova, K., Spell, C. S., Perry, J. L., \& Jehn, K. A. (2016). A meta-analytical integration of over 40 years of research on diversity training evaluation. Psychological Bulletin, 142(11), 1227- 1274. https://doi.org/10.1037/bul0000067

Cording, M., Harrison, J. S., Hoskisson, R. E., \& Jonsen, K. (2014). Walking the talk: A multistakeholder exploration of organizational authenticity, employee productivity, and post-merger performance. Academy of Management Perspectives, 28(1), 38-56. https://doi.org/10.5465/amp.2013.0002

Cox, T. H., \& Blake, S. (1991). Managing cultural diversity: Implications for organizational competitiveness. Academy of Management Perspectives, 5(3), 45-56. https://doi.org/10.5465/ame.1991.4274465

Cropanzano, R., \& Mitchell, M. S. (2005). Social exchange theory: An interdisciplinary review. Journal of Management, 31(6), 874-900. https://doi.org/10.1177/0149206305279602

DeNisi, A. S., Randolph, W. A., \& Blencoe, A. G. (1983). Potential problems with peer ratings. Academy of Management Journal, 26(3), 457-464. https://doi.org/10.5465/256256

Dutton, J. E., Dukerich, J. M., \& Harquail, C. V. (1994). Organizational images and member identification. Administrative Science Quarterly, 239-263. https://doi.org/10.2307/2393235

Douglas, K. M., \& Leite, A. C. (2017). Suspicion in the workplace: Organizational conspiracy theories and work-related outcomes. British Journal of Psychology, 108(3), 486-506. https://doi.org/10.1111/bjop.12212

Dwertmann, D. J., Nishii, L. H., \& Van Knippenberg, D. (2016). Disentangling the fairness \& discrimination and synergy perspectives on diversity climate: Moving the field forward. Journal of Management, 42(5), 1136-1168. https://doi.org/10.1177/0149206316630380 
Eisend, M. (2006). Two-sided advertising: A meta-analysis. International Journal of Research in Marketing, 23(2), 187-198. https://doi.org/10.1016/j.ijresmar.2005.11.001

Ely, R. J., \& Thomas, D. A. (2001). Cultural diversity at work: The effects of diversity perspectives on work group processes and outcomes. Administrative Science Quarterly, 46: 229-273. https://doi.org/10.2307/2667087

Ely, R. J., Meyerson, D. E., \& Davidson, M. N. (2006). Rethinking political correctness. Harvard Business Review, 84(9), 78-86. Retrieved from https://hbr.org/2006/09/rethinking-political-correctness

Field, A. 2018. Discovering statistics using SPSS (3rd ed.). London: Sage.

Gardner, W. L., Cogliser, C. C., Davis, K. M., \& Dickens, M. P. (2011). Authentic leadership: A review of the literature and research agenda. The Leadership Quarterly, 22(6), 1120-1145. https://doi.org/10.1016/j.leaqua.2011.09.007

Guillaume, Y. R., Dawson, J. F., Priola, V., Sacramento, C. A., Woods, S. A., Higson, H. E., Budhwar, P.S., \& West, M. A. (2014). Managing diversity in organizations: An integrative model and agenda for future research. European Journal of Work and Organizational Psychology, 23(5), 783-802. https://doi.org/10.1080/1359432X.2013.805485

Guillaume, Y. R., Dawson, J. F., Otaye-Ebede, L., Woods, S. A., \& West, M. A. (2017). Harnessing demographic differences in organizations: What moderates the effects of workplace diversity?. Journal of Organizational Behavior, 38(2), 276-303. https://doi.org/10.1002/job.2040

Halsey, L. G., Curran-Everett, D., Vowler, S. L., \& Drummond, G. B. (2015). The fickle P value generates irreproducible results. Nature Methods, 12(3), 179-187. Retrieved from https://labs.la.utexas.edu/gilden/files/2016/03/out.pdf

Hayes, A. F. (2018). An index and test of linear moderated mediation. Multivariate Behavioral Research, 50(1), 1-22. http://doi.org/10.1080/00273171.2014.962683

Hogg, M. A., \& Terry, D. I. (2000). Social identity and self-categorization processes in organizational contexts. Academy of Management Review, 25(1), 121-140. https://doi.org/10.5465/amr.2000.2791606

Jordan, J. J., Sommers, R., Bloom, P., \& Rand, D. G. (2017). Why do we hate hypocrites? Evidence for a theory of false signaling. Psychological Science, 28(3), 356-368. https://doi.org/10.1177/0956797616685771

Kalev, A., Dobbin, F., \& Kelly, E. (2006). Best practices or best guesses? Assessing the efficacy of corporate affirmative action and diversity policies. American Sociological Review, 71(4), 589-617. https://doi.org/10.1177/000312240607100404

King, E. B., Dawson, J. F., West, M. A., Gilrane, V. L., Peddie, C. I., \& Bastin, L. (2011). Why organizational and community diversity matter: Representativeness and the emergence of incivility and organizational performance. Academy of Management Journal, 54(6), 1103-1118. https://doi.org/10.5465/amj.2010.0016

Kirkland, R. \& Bohnet, I. (2017, April) Focusing on what works for workplace diversity. Retrieved from https://www.mckinsey.com/featured-insights/gender-equality/focusing-on-what-works-forworkplace-diversity

Kooij, D. T., Jansen, P. G., Dikkers, J. S., \& De Lange, A. H. (2010). The influence of age on the associations between HR practices and both affective commitment and job satisfaction: A metaanalysis. Journal of Organizational Behavior, 31(8), 1111-1136. https://doi.org/10.1002/job.666

Lee, S., \& Yoon, J. (2018). Does the authenticity of corporate social responsibility affect employee commitment?. Social Behavior And Personality: An International Journal, 46(4), 617-632. https://doi.org/10.2224/sbp.6475 
Leroy, H., Palanski, M. E., \& Simons, T. (2012). Authentic leadership and behavioral integrity as drivers of follower commitment and performance. Journal of Business Ethics, 107(3), 255-264. https://doi.org/10.1007/s10551-011-1036-1

Leslie, L. M. (2019). Diversity Initiative Effectiveness: A Typological Theory of Unintended Consequences. Academy of Management Review, Advance online publication. https://doi.org/10.5465/amr.2017.0087

McKay, P. F., Avery, D. R., Tonidandel, S., Morris, M. A., Hernandez, M., \& Hebl, M. R. (2007). Racial differences in employee retention: Are diversity climate perceptions the key?. Personnel psychology, 60(1), 35-62. https://doi.org/10.1111/j.1744-6570.2007.00064.x

Meyer, J. P., \& Allen, N. J. (1991). A three-component conceptualization of organizational commitment. Human Resource Management Review, 1(1), 61-89. https://doi.org/10.1016/1053-4822(91)90011$\mathrm{Z}$

Meyer, J. P., Stanley, D. J., Herscovitch, L., \& Topolnytsky, L. (2002). Affective, continuance, and normative commitment to the organization: A meta-analysis of antecedents, correlates, and consequences. Journal of Vocational Behavior, 61(1), 20-52. https://doi.org/10.1006/jvbe.2001.1842

Olsen, J. E., \& Martins, L. L. (2012). Understanding organizational diversity management programs: A theoretical framework and directions for future research. Journal of Organizational Behavior, 33(8), 1168-1187. https://doi.org/10.1002/job.1792

Pechmann, C. (1992). Predicting when two-sided ads will be more effective than one-sided ads: The role of correlational and correspondent inferences. Journal of Marketing Research, 29(4), 441-453. https://doi.org/10.1177/002224379202900405

Pettigrew, T. F., \& Tropp, L. R. (2006). A meta-analytic test of intergroup contact theory. Journal of Personality and Social Psychology, 90(5), 751-783. https://psycnet.apa.org/doi/10.1037/00223514.90.5.751

Podsakoff, P. M., \& Podsakoff, N. P. (2019). Experimental designs in management and leadership research: Strengths, limitations, and recommendations for improving publishability. The Leadership Quarterly. https://doi.org.10.1016/j.leaqua.2018.11.002

Robinson, S. L. (1996). Trust and breach of the psychological contract. Administrative Science Quarterly, 574-599. https://doi.org/10.2307/2393868

Rousseau, D. M. \& Parks, J. M. (1993). The contracts of individuals and organizations. Research in Organizational Behavior, 15, 1-43. Retrieved from http://web.mit.edu/curhan/www/docs/Articles/15341_Readings/Justice/TheContractsOfIndividuals AndOrganizations_RosseauParks.pdf

Rynes, S., \& Rosen, B. (1995). A field survey of factors affecting the adoption and perceived success of diversity training. Personnel Psychology, 48(2), 247-270. https://doi.org/10.1111/j.17446570.1995.tb01756.x

Sidak, Z. (1967). Rectangular confidence regions for the means of multivariate normal distributions. Journal of the American Statistical Association, 62: 626-633. https://doi.org/10.2307/2283989

Simons, T., Friedman, R., Liu, L. A., \& McLean Parks, J. (2007). Racial differences in sensitivity to behavioral integrity: Attitudinal consequences, in-group effects, and" trickle down" among Black and non-Black employees. Journal of Applied Psychology, 92(3), 650-681. https://doi.org/10.1037/0021-9010.92.3.650

Simons, T., Leroy, H., Collewaert, V., \& Masschelein, S. (2015). How leader alignment of words and deeds affects followers: A meta-analysis of behavioral integrity research. Journal of Business Ethics, 132(4), 831-844. https://doi.org/10.1007/s10551-014-2332-3 
Simons, T. (2002). Behavioral integrity: The perceived alignment between managers' words and deeds as a research focus. Organization Science, 13(1), 18-35. https://doi.org/10.1287/orsc.13.1.18.543

Smidts, A., Pruyn, A. T. H., \& Van Riel, C. B. (2001). The impact of employee communication and perceived external prestige on organizational identification. Academy of Management Journal, 44(5), 1051-1062. https://doi.org/10.5465/3069448

Smith, A. N., Morgan, W. B., King, E. B., Hebl, M. R., \& Peddie, C. I. (2012). The ins and outs of diversity management: The effect of authenticity on outsider perceptions and insider behaviors. Journal of Applied Social Psychology, 42, 21-55. https://doi.org/10.1111/j.15591816.2012.01021.x

Tajfel, H., \& Turner, J. (1986). The social identity theory of intergroup behaviour.. In S. Worchel, \& W.G. Austin (Eds.), Psychology of intergroup relations ( $2^{\text {nd }}$ ed., pp. 7-24). Chicago: Nelson Hall.

Tett, R. P., \& Meyer, J. P. (1993). Job satisfaction, organizational commitment, turnover intention, and turnover: path analyses based on meta-analytic findings. Personnel Psychology, 46(2), 259-293. https://doi.org/10.1111/j.1744-6570.1993.tb00874.x

Turban, D. B., \& Greening, D. W. (1997). Corporate social performance and organizational attractiveness to prospective employees. Academy of Management Journal, 40(3), 658-672. https://doi.org/10.5465/257057

Valdesolo, P., \& DeSteno, D. (2008). The duality of virtue: Deconstructing the moral hypocrite. Journal of Experimental Social Psychology, 44(5), 1334-1338. https://doi.org/10.1016/j.jesp.2008.03.010

Vandenberghe, C., \& Bentein, K. (2009). A closer look at the relationship between affective commitment to supervisors and organizations and turnover. Journal of Occupational and Organizational Psychology, 82(2), 331-348. https://doi.org/10.1348/096317908X312641

Van Knippenberg, D. (2000). Work motivation and performance: A social identity perspective. Applied Psychology, 49(3), 357-371. https://doi.org/10.1111/1464-0597.00020

Van Knippenberg, D., \& Sleebos, E. (2006). Organizational identification versus organizational commitment: self - definition, social exchange, and job attitudes. Journal of Organizational Behavior, 27(5), 571-584. https://doi.org/10.1002/job.359

van Knippenberg, D., \& Schippers, M. C. (2007). Work group diversity. Annual Review of Psychology, 58, 515-541. https://doi.org/10.1146/annurev.psych.58.110405.085546

Wagner, T., Lutz, R. J., \& Weitz, B. A. (2009). Corporate hypocrisy: Overcoming the threat of inconsistent corporate social responsibility perceptions. Journal of Marketing, 73(6), 77-91. https://doi.org/10.1509/jmkg.73.6.77

Windscheid, L., Bowes-Sperry, L., Kidder, D. L., Cheung, H. K., Morner, M., \& Lievens, F. (2016). Actions speak louder than words: Outsiders' perceptions of diversity mixed messages. Journal of Applied Psychology, 101(9), 1329-1341. https://doi.org/10.1037/apl0000107 


\section{Table 1}

Study 1: Means, Standard Deviations, and Correlations among Key Variables

\begin{tabular}{|c|c|c|c|c|c|c|c|c|}
\hline Variable & & $\begin{array}{l}\text { Mean } \\
(S D)\end{array}$ & 2 & 3 & 4 & 5 & 6 & 7 \\
\hline 1. & $\begin{array}{l}\text { Demographic } \\
\text { Representativeness }\end{array}$ & $.49(.50)$ & -.03 & $.48 * *$ & $.17 *$ & $.21 * *$ & .10 & .07 \\
\hline 2. & DM Approach & $.51(.50)$ & & -.06 & .01 & -.01 & -.05 & .02 \\
\hline 3. & $\begin{array}{l}\text { Perceived Organizational } \\
\text { Authenticity }\end{array}$ & $\begin{array}{l}4.66 \\
(1.42)\end{array}$ & & & $.52 * *$ & $.59 * *$ & .13 & -.05 \\
\hline 4. & Affective Commitment & $\begin{array}{l}4.39 \\
(1.09)\end{array}$ & & & & $.84 * *$ & $.17 *$ & .00 \\
\hline & $\begin{array}{l}\text { Organizational } \\
\text { Identification }\end{array}$ & $\begin{array}{l}4.62 \\
(1.16)\end{array}$ & & & & & $.18^{*}$ & -.01 \\
\hline 6. & Age & $\begin{array}{l}26.03 \\
(7.73)\end{array}$ & & & & & & .09 \\
\hline 7. & Gender & $.66(.50)$ & & & & & & \\
\hline
\end{tabular}

Note. $N=192$. DR dummy coded $0=$ High DR, $1=$ Low DR. DM Approach dummy coded $0=$ Instrumental, $1=$ Terminal. Gender dummy coded $0=$ Male, $1=$ female. All other variables were scored on a 7 -point scale $(1=$ Strongly disagree, $7=$ Strongly agree). $* p<.05, * * p<.01$

\section{Table 2}

Study 1: Means, Standard Deviations, and Cell Sizes for Each Condition

\begin{tabular}{|c|c|c|c|c|c|}
\hline \multicolumn{6}{|c|}{ Condition } \\
\hline & & $\begin{array}{l}\text { High DR / } \\
\text { Instrumental }\end{array}$ & $\begin{array}{l}\text { Low DR / } \\
\text { Instrumental }\end{array}$ & $\begin{array}{l}\text { High DR / } \\
\text { Terminal }\end{array}$ & Low DR / Terminal \\
\hline \multicolumn{2}{|c|}{ Cell Sizes } & $N=50$ & $N=45$ & $N=48$ & $N=49$ \\
\hline 1. & $\begin{array}{l}\text { Perceived } \\
\text { Organizational } \\
\text { Authenticity }\end{array}$ & $5.46(.96)$ & $3.60(1.59)$ & $5.20(1.01)$ & $4.29(1.29)$ \\
\hline 2. & $\begin{array}{l}\text { Affective } \\
\text { Commitment }\end{array}$ & $4.69(1.01)$ & $4.07(1.07)$ & $4.43(1.15)$ & $4.33(1.06)$ \\
\hline & $\begin{array}{l}\text { Organizational } \\
\text { Identification }\end{array}$ & $4.94(1.03)$ & $4.22(1.28)$ & $4.75(1.10)$ & $4.51(1.14)$ \\
\hline
\end{tabular}

Note: Values represent means and (standard deviations)

Table 3

Study 2: Means, Standard Deviations, Confidence Intervals, and Correlations among Key Variables

\begin{tabular}{|c|c|c|c|c|c|c|}
\hline \multicolumn{2}{|l|}{ Variable } & \multirow{2}{*}{$\begin{array}{l}\text { Mean }(S D \\
) \\
.49(.50)\end{array}$} & \multirow{2}{*}{$\begin{array}{l}2 \\
-.25^{*}\end{array}$} & \multirow{2}{*}{$\begin{array}{l}3 \\
.09\end{array}$} & \multirow{2}{*}{$\begin{array}{l}4 \\
\\
.00\end{array}$} & \multirow{2}{*}{$\begin{array}{l}5 \\
.10\end{array}$} \\
\hline 1. & Honest Hypocrite Condition & & & & & \\
\hline 2. & $\begin{array}{l}\text { Perceived Organizational } \\
\text { Authenticity }\end{array}$ & $3.58(1.35)$ & & $.45^{* *}$ & $.50 * *$ & $.19 *$ \\
\hline 3. & Affective Commitment & $3.83(.96)$ & & & $.85^{* *}$ & .11 \\
\hline 4. & Organizational Identification & $3.93(1.10)$ & & & & .13 \\
\hline 5. & Gender & $.55(.50)$ & & & & \\
\hline
\end{tabular}

Note $\mathrm{N}=91$. Condition dummy coded $0=$ Hypocritical, $1=$ Honest hypocrite. Gender dummy coded $0=$ Male, $1=$

Female. All other variables were scored on a 7 -point scale $(1=$ Strongly disagree, $7=$ Strongly agree $) * p<.05, * * p<.01$ 
Table 4

Study 3: Means, Standard Deviations, Confidence Intervals, and Correlations among Key Variables

\begin{tabular}{|c|c|c|c|c|c|c|}
\hline Variable & & $\begin{array}{l}\text { Mean } \\
(S D)\end{array}$ & 2 & 3 & 4 & 5 \\
\hline 1. & Honest Hypocrite Condition & $.50(.50)$ & $.30 * *$ & $.24 * *$ & $.25^{* *}$ & .09 \\
\hline 2. & $\begin{array}{l}\text { Perceived Organizational } \\
\text { Authenticity }\end{array}$ & $\begin{array}{l}3.58 \\
(1.35)\end{array}$ & & $.61 * *$ & $.65^{* *}$ & .10 \\
\hline 3. & Affective Commitment & $3.83(.96)$ & & & $.81 * *$ & .11 \\
\hline 4. & Organizational Identification & $\begin{array}{l}3.93 \\
(1.10)\end{array}$ & & & & .10 \\
\hline 5. & Gender & & & & & \\
\hline
\end{tabular}

Note. $N=175$. Condition dummy coded $0=$ Hypocritical, $1=$ Honest hypocrite. Gender dummy coded $0=$ Male, $1=$ Female. All other variables were scored on a 7 -point scale $(1=$ Strongly disagree, $7=$ Strongly agree $) . * p<.05, * * p<$ .01

Table 5

Study 4: Means, Standard Deviations, Confidence Intervals, and Correlations Among Key

\begin{tabular}{|c|c|c|c|c|c|c|c|c|c|}
\hline Variable & & $\begin{array}{l}\text { Mean } \\
(\mathrm{SD})\end{array}$ & 2 & 3 & 4 & 5 & 6 & 7 & 8 \\
\hline 1. & $\begin{array}{l}\text { Perceived } \\
\text { Organizational } \\
\text { Authenticity }\end{array}$ & $\begin{array}{l}4.71 \\
(1.39)\end{array}$ & $.55^{* *}$ & $.61 * *$ & $-.60 * *$ & $.62 * *$ & .12 & $-.21 * *$ & .10 \\
\hline 2. & $\begin{array}{l}\text { Affective } \\
\text { Commitment }\end{array}$ & $\begin{array}{l}3.95 \\
(1.51)\end{array}$ & & $.86^{* *}$ & $-.29 * *$ & $.48 * *$ & .10 & $-.22 * *$ & $.15^{*}$ \\
\hline 3. & $\begin{array}{l}\text { Organizational } \\
\text { Identification }\end{array}$ & $\begin{array}{l}4.37 \\
(1.44)\end{array}$ & & & $-.33 * *$ & $.55^{* *}$ & .13 & $-.21 * *$ & $.14 *$ \\
\hline 4. & $\begin{array}{l}\text { Espoused - } \\
\text { Practiced DM } \\
\text { discrepancy }\end{array}$ & $.48(.80)$ & & & & $-.32 * *$ & -.13 & .13 & -.02 \\
\hline 5. & Diversity Climate & $\begin{array}{l}3.07 \\
(.75)\end{array}$ & & & & & .01 & .03 & .09 \\
\hline 6. & Age & $\begin{array}{l}38.49 \\
(10.26)\end{array}$ & & & & & & $-.16^{*}$ & $.35^{* *}$ \\
\hline 7. & Org Size & $\begin{array}{l}4.27 \\
(1.50)\end{array}$ & & & & & & & $.22 * *$ \\
\hline 8. & Tenure & $\begin{array}{l}3.32 \\
(1.36)\end{array}$ & & & & & & & \\
\hline
\end{tabular}

Note. $N=200 . * p<.05, * * p<.01$

Figure 2

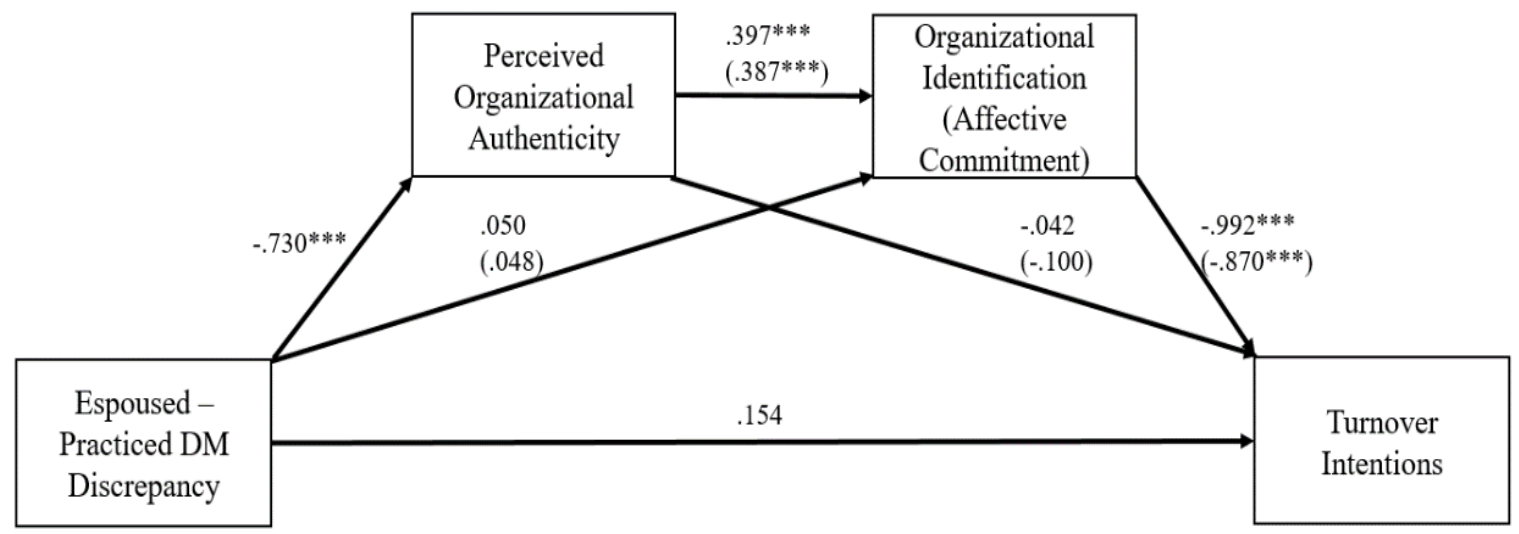

Note. Unstandardized $B$ coefficients for sequential mediation analyses using PROCESS Macro model 6. Coefficients in (parentheses) are for the model including affective commitment. Diversity climate, organization size, employee age, and tenure entered as covariates. $* * * p<.001 .{ }^{* *} p<.01 . * p<.001$ 


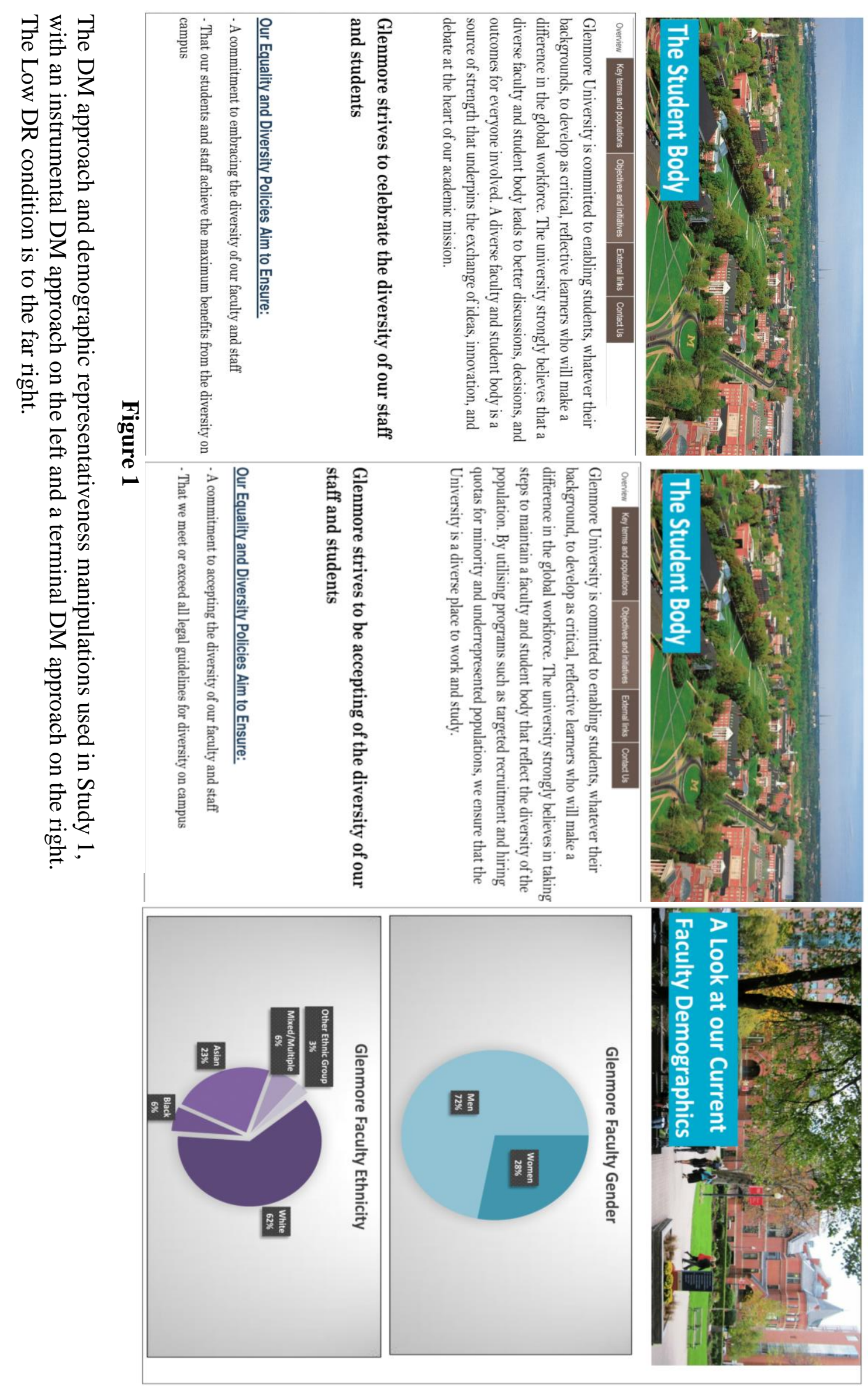

